\title{
HEALTH EDUCATION INTERVENTION ON HIV/AIDS AMONG THE URBAN SLUM DWELLERS OF DIBRUGARH, ASSAM
}

Forhad Akhtar Zaman, Samuel Sheikh, Gaffar Sarwar Zaman

1. Associate Professor. Department of Community Medicine, Sikkim Manipal Institute of Medical Sciences \& Central Referral Hospital.

2. Assistant Professor. Department of Zoology, BN College. Dhubri, Assam.

3. Assistant Professor. Department of Biochemistry, College of Medicine, King Khaled University, Abha, Saudi Arabia.

\section{CORRESPONDING AUTHOR:}

Dr. Forhad Akhtar Zaman,

Associate Professor, Community Medicine,

Sikkim Manipal Institute of Medical Sciences (SMIMS) and

Central Referral Hospital (CRH),

$5^{\text {th }}$ Mile, Tadong, Gangtok, Sikkim, India- 737102.

E-mail: drforhadzaman@rediffmail.com

ABSTRACT: BACKGROUNDS: HIV/AIDS has become the most challenging as well as dreaded phenomenon in the global epidemiological transition and has become truly universal threat to civilization. OBJECTIVE: To evaluate the impact of Information, Education \& Communication (IEC) on Knowledge, Attitude \& Practice (KAP) on HIV/AIDS among the slum dwellers of Dibrugarh using the standard IEC package for urban slums formulated by the National AIDS Control Organization (NACO). METHODS: A total of 246 slum dwellers aged 15-49 years were selected from all the slums of Dibrugarh by stratified systematic random sampling method. The study was conducted in three stages. First a baseline KAP survey on HIV/AIDS was done followed by health education intervention (IEC). Just after the intervention and after three months period, the evaluation of the intervention was conducted. RESULTS: $87 \%$ of the respondents were found to have heard of HIV/AIDS. Baseline Knowledge regarding prevention of transmission of HIV/AIDS by having one faithful sex partner was there among $65 \%$ of the respondents which increased amongst $82.2 \%$ of the respondents just after the intervention \& amongst $68.5 \%$ of the respondents after three months period; similarly knowledge of prevention by using condom, increased from $70.7 \%$ to $80.3 \%$ \& $76.3 \%$ of the respondents; using safe blood, increased from $57.7 \%$ to $75.4 \% \& 62.9 \%$ of the respondents. CONCLUSIONS: From the above findings it was evident that, intervention programs were useful in enhancing the awareness regarding HIV/AIDS among the underprivileged population.

KEY WORDS: HIV/AIDS, Intervention, KAP

INTRODUCTION: AIDS is considered a dreaded disease as no effective vaccine or drug therapy is available. Mass media campaigns and interpersonal communication by non-government organization (NGO's) have succeeded in raising the level of awareness about AIDS in the general population in urban areas. Therefore, Government of India launched an intensive programme to create awareness about AIDS and to provide services for sexually transmitted diseases (STDs) and reproductive tract infections (RTIs) through family awareness campaigns. In 1999 the Government of India initiated a family health awareness campaign under the National AIDS Control Programme with the objectives of increasing the awareness of HIV/AIDS in rural areas and in other vulnerable groups of the population, and identifying high risk groups for a targeted 
intervention programme. Multi-pronged strategies are used to reach the masses for creating awareness about AIDS. Nearly half of our respondents at baseline and over four-fifth after intervention considered the mass media (TV, radio, etc.) as sources of information regarding AIDS. Camps and health workers are important contributors, but the immense effort made by them could not achieve the desired level of awareness. TVs and radios are present in almost all households and are a good, cheap, and effective channel.

HIV/AIDS was first identified among the homosexual community of developed nations in North America and Europe in late 1970s. [1] The prevalence of HIV cases has increased at an alarming rate since then. There was no treatment and apparently no way to stop the spread of HIV infection except by engaging in dubious efforts to change people's behavior.

Since the detection of the first case in India in 1986 in Chennai, 22.7 lakh confirmed cases of AIDS have been reported in India as per the HIV estimate of 2008-9. [2] Due to the absence of a potent vaccine or/and effective treatment, the only weapon we have at our hand is prevention aimed at increasing awareness of HIV/AIDS.

Assam is still among the low prevalence states of India, with 863 confirmed cases of AIDS reported as per the HIV estimate of 2008-9. [3] The geographical location of Assam adjoining high prevalence states like Manipur and Nagaland will probably make it a high risk zone in the coming years if appropriate intervention measures are not taken adequately beforehand.

Till now very little interventional studies has been done in Assam to find the effectiveness and impact of intervention regarding HIV/AIDS. Prompted by this above fact, the present study was undertaken among the urban slum dwellers of Dibrugarh.

METHODS: This was a quasi experimental study of an intervention without control group carried out from August 2007 to July 2008 among 246 slum dwellers aged 15-49 years of Dibrugarh, Assam.

SAMPLE SIZE: The sample size was calculated by using the formula

$\mathrm{z}^{2} \mathrm{pq}$

Sample size $=$

$d^{2}$

Where, $\mathrm{z}=1.96$

$\mathrm{p}=$ previous prevalence

$q=1-p$

$d=$ allowable errors (using $10 \%$ to $20 \%$ of ' $p$ ')

Report of behavioral Surveillance Survey (BSS) of 2001conducted by NACO under NACP - II [4] observed that $30.1 \%$ persons of urban India had knowledge of HIV/AIDS prevention methods. It is for this reason that the prevalence of the knowledge of HIV/AIDS/STD was taken to be $30 \%$. Now considering ' $p$ ' to be $30 \%$ and taking allowable error to be $20 \%$ of ' $p$ ', the 
sample size was estimated to be 224 . In selecting the sample units, $10 \%$ non response was considered and thus the sample size was inflated to $224+22=246$.

SAMPLING METHOD: Stratified systematic random sampling technique was used for selecting the sample. The study area selected included 10 registered urban slums of Dibrugarh town. Considering each of the slum areas as strata, the sample size which was calculated to be 246 was allocated proportionally to each of these slums. The selection of the houses in those slums was done by picking up a random starting number and then every $\mathrm{n}^{\text {th }}$ house was visited. $\mathrm{N}$-th house was found out by dividing the total population of that particular slum by the proportionally allocated sample size in that slum. The eligible samples (both male \& female aged 15-49 years) from those selected houses were then interviewed and given intervention \& this was done till the required sample size in each slum area was obtained. In case of refusal, it was not replaced but the next nth house was visited. If any house was found to be locked or if no one was available, then the next house was taken as replacement, continuing with the original sampling units (every nth house) after that.

DATA COLLECTION INSTRUMENT: The questionnaire contained all the questions relating to the evaluation and assessment of knowledge, attitude and practice of HIV/AIDS \& it was predesigned and pretested. The questionnaire was developed at the Institute with the assistance from the faculty members and other experts in this field. By initial translation, backtranslation, retranslation, followed by pilot study the module was custom-made for the study. Modifications of the questions from the interview schedule were done following a pilot study. All the participants were motivated, explained about the purposes of the study, and ensured strict confidentiality and exclusive use of collected data for academic purposes along with the scope of future intervention. The participants were given the option of withdrawing from the study if they wanted. Informed consent was taken from each of the participant before the study.

DATA COLLECTION PROCEDURE: The study conformed to the Helsinki declaration \& Institution ethical committee (IEC) approved the study. The principal investigator collected the information in the standard questionnaire format on HIV/AIDS from people in the age group of 15-49 years in those identified slums. The study was conducted in three stages. First a baseline KAP survey on HIV/AIDS was done among the sample population. In the second stage the principal investigator commented on the relevance of the topic and then initiated the interactive discussions with intricate questions and then put the participants on dynamic learning. An intensive IEC intervention was carried out through interpersonal communication technique, (one to one counseling in a single session) The IEC tool used was the standard IEC package for urban slums formulated by NACO. ${ }^{[5]}$ At the end of the IEC intervention sessions, the participants were asked to provide feedback using the same set of schedules with some added questions. In the third and final stage, another survey was done after three months using the same set of schedules with some added questions among the same sample population. Excluding the 9 who were non respondents of the 246 slum dwellers, 237 was the final sample size. Total follow up loss (three months after Intervention) was 17(7.4\%) among which 9 were females and 8 were males.

STATISTICAL ANALYSIS: The results were expressed in percentages represented by tables and statistically analyzed using chi-square test. 
RESULTS: Of the participants, $108(45.57 \%)$ were male and $129(54.43 \%)$ were female; 156 $(65.82 \%)$ were married. Most of the male study subjects $(29.6 \%)$ were engaged in unskilled work. Overall $208(87.76 \%)$ had heard of HIV/AIDS. Maximum number of study subjects (57.69\%) had cited TV as their source of knowledge regarding HIV/AIDS followed by health education (FHAC) (31.25\%). (Table-1)

Before Intervention, 65.8 percent of the study subjects knew at least two modes of prevention of HIV/AIDS. Just after Intervention and three months after Intervention, the knowledge of at least two modes of prevention of HIV/AIDS was found among 78.4 percent and 68.5 percent of the study subjects. The difference of values among both males \& females before Intervention \& three months after Intervention was statistically insignificant ( $p>0.05$ ).

Before Intervention, 76 percent of the study subjects had at least one misconception about the modes of prevention of HIV/AIDS. Just after Intervention and three months after Intervention this misconception was there amongst 24 percent and 48.4 percent of the study subjects respectively. This difference of values among the study subjects before Intervention \& just after Intervention and before Intervention \& three months after Intervention was statistically significant $(\mathrm{p}<0.05)$.

Before Intervention, 70.7 percent of the study subjects knew that HIV/AIDS can be prevented by using condom consistently with non regular sexual partner. Just after Intervention and three months after Intervention this observation increased up to 80.3 percent and 76.3 percent of the study subjects respectively. 10.2 percent males and 2.3 percent females reported sexual intercourse with a non regular partner/CSW during the past twelve months. 50 percent of the study subjects reported the use of condom in the last sexual act with a non regular partner. Three months after Intervention, 28.6 percent of the study subjects made changes in their high risk behavior to avoid HIV/AIDS (Table-3)

DISCUSSION: Targeted Intervention (TI) programmes are important strategies of the National AIDS Control Programme in India. The present study was conducted in Assam to find out the effectiveness and impact of intervention regarding HIV/AIDS. Its results reflect the effect of the intervention carried out through interpersonal communication technique.

In the present study it was observed that $87.7 \%$ of the study subjects had heard of HIV/AIDS.

This finding was comparable with the finding observed in the Behavioral Surveillance Survey conducted by NACO in $2001 .{ }^{[4]}$ In a similar study, $68 \%$ of the persons were aware of HIV/AIDS in 1999 as against $49 \%$ in 1996. [6]

In Kargil, a community based survey in the reproductive age group population reported that only one-fifth were aware of AIDS; this was probably due to reasons like the orthodox population, low female literacy, low sex ratio and issues related to sexuality being taboo. [7]

Many studies and IEC interventions have been reported in India in different age groups and settings with a wide range of AIDS awareness levels, e.g. 13.5\% school students and 16.2\% teachers had knowledge about AIDS in Calcutta, ${ }^{[8]}$ 83.3\%-100\% students were aware in Maharashtra, ${ }^{[9]}$ and $83 \%$ of child development project officers (ICDS) in Delhi knew about AIDS. [10] Significant improvement was seen in the areas of sex and AIDS knowledge during the posttraining phase in students in Pune. [11]

In the present study, maximum number of study subjects $(57.7 \%)$ had cited TV as their source of knowledge regarding HIV/AIDS. This observation was comparable to that observed in the Rapid Household Survey done under RCH in 1998. [12] Bhatia et al in Chandigarh also 
observed a similar finding. In both the studies, the main source of knowledge was from the electronic and print media. [13]

The findings of the present study was almost similar with the observations made in the Rapid Household Survey of RCH where it was found that a substantial number of males and females (Male-72\%; Female-74.5\%) had misconception about the different transmission modes of HIV/AIDS. [12]

This study revealed that the IEC intervention has significantly increased the knowledge \& positive attitude of the study population but the sad part of the findings is that this increase in knowledge could not be sustained to the same extent after 3 months as it was just after the intervention. Bhatia et al in an interventional study to enhance AIDS awareness among the underprivileged population in slum areas of Chandigarh observed that awareness about AIDS increased from 58.2 to 70 percent. Knowledge regarding prevention of AIDS by using condom increased from 42 to 61.2 percent; having a single partner, from 59 to 72.3 percent; and using safe blood, from 14.9 to 29 percent. They found that knowing about HIV/AIDS did not mean that the community was aware about its various modes of transmission and the means to prevent it. Over $70 \%$ of the respondents were aware of unsafe sex/multiple sex partners as a mode of transmission but few were aware of blood transfusion and the use of nonsterile needles and syringes; even intervention left nearly half unaware about these modes. Vertical transmission as a mode was known only to a few subjects. The use of condoms and having a single partner for sex to prevent AIDS was known to $61.2 \%$ and $72.3 \%$ of the subjects respectively after the intervention phase. Sex was considered to be an important mode of transmission. Though the FHAC led to increased awareness regarding the various routes of transmission and preventive measures, yet more than two-thirds were not aware about the role of needles/syringes and safe blood. The increase in knowledge about condoms from $42 \%$ in the pre-intervention phase to $61.2 \%$ in the post-intervention phase is an important gain. Use of condoms by the community can lead to a remarkable decline in HIV/AIDS and STD prevalence. The family health awareness campaign is a remarkable effort to reach the community but the momentum has to be sustained. A large section of society is poor and still lacks basic knowledge about AIDS, its spread and prevention. While a onetime activity such as FHAC can enhance the knowledge as in the present study, activities such as awareness campaign, IEC activities, camps, mass media, and involvement of community leaders must be consistently implemented and their achievements assessed by regular evaluation. [13]

The Sonagachi Intervention Project increased the proportion that had an optimistic attitude and increased prevention and treatment-seeking behavior. [14] A model has suggested that a successful sex worker intervention in India would drive the HIV/AIDS epidemic to extinction. [15]

In a similar study, it was observed that with intervention, there was an improvement in the knowledge; however the proportion of students with misconceptions did not come down. Correct knowledge about two methods of prevention also did not reach the WHO recommendation of $90 \%$. [16]

A study conducted by Raizada $\mathrm{N}$ et al (2004) among the school going teenagers in Jamnagar city of Gujarat observed that HIV related stigma was highly prevalent among adolescents. In the same study it was observed that inter personal communication emerged as the most effective IEC in reducing negative attitude towards HIV positive persons and increasing knowledge regarding HIV/AIDS. [17] 
Prabhakaran.B (2003) in a Behavioral Surveillance Survey (BSS) in Maharashtra found that fewer than $3 \%$ of 15-19 years old male youth from slum areas reported sexual contact with a commercial partner in the previous twelve months. Only two-third of them reported consistent use of condom with commercial partners. [18] Studies report a 69\%-87\% reduction in the risk of contracting STDs, including gonorrhea, chlamydial infection, trichomoniasis and HIV infection, by using condoms. [19]

The difference of findings about reported sexual contact with non-regular partner in a twelve month recall period in the present study and some other studies like the BSS survey of 2001 by NACO may be because of the fact that correct assessment of sexual behavior of the people was solely dependent on the information given by the study subjects which may not be always true. [5]

Agha, S. and Van Rossem, R. (2004) in a School Based Youth Targeted Programme observed that students reported significant reduction in multiple sexual partnerships during the second follow up after six months. [20]

CONCLUSION: Target specific intervention programmes are at the centre stage of the planning of the National AIDS Control Programme in India. The present study was conducted as a part of a general health awareness campaign. The recent National AIDS Control Policy of the Government of India aims at preventing the spread of AIDS by making people aware of its implications and providing them with the necessary tools for protecting themselves. A large section of society is poor and still lacks basic knowledge about AIDS, its spread and prevention. While a onetime activity such as done in this study has enhanced the knowledge, activities such as awareness campaign, IEC activities, camps, mass media, and involvement of community leaders must be consistently implemented and their achievements assessed by regular evaluation. Repeated periodical Interventions on HIV/AIDS should be done which will be more useful in achieving the desired positive outcome on prevention of HIV/AIDS. More intensive awareness creating programme should be developed by the Government to raise the level of awareness about STD amongst the general population. Condom promotion efforts should be more vigorous. IEC intervention can only marginally improve awareness about HIV/AIDS. Moreover, how much this favorable improvement about awareness and attitudes is going to be permanent and translate into behavior could not be ascertained from the study. Ongoing behavior change communication and repeated studies to assess the impact of such measures may resolve these issues.

\section{REFERENCES:}

1. AIDS \& HIV infection - Information for UN Employees and their families. WHO Geneva, $1991 \mathrm{pg}-48$.

2. Annual report 2009-10, Department of AIDS control, MOHFW, Pg-1.

3. Report on field survey conducted by Town \& Country planning, Dibrugarh 2001, page no- 37.

4. Report of Behavioral Surveillance Survey (BSS) of 2001 by NACO under NACP-II http: www.naco.nic.in.

5. NACO Programmes- Information, Education, Communication \& Social Mobilization. http: www.naco.nic.in.

6. Lal S. Building awareness on AIDS/HIV through intensive campaign on pilot basis. Ind J Comm Med 1999; 24:47-9. 
7. Ahmed M, Gaash B. Awareness of HIV/AIDS in a remotely located conservative district of J\&K (Kargil). Results of a community based study. Ind J Com Med 2002;27:12-8.

8. Chatterjee C, Baus B, Ram R, Dhas G, Sandhu Khan S, Dan A. A study on awareness of AIDS among school students and teachers of higher secondary schools in North Calcutta. Ind J Pub Health 2001; 45:27-30.

9. Ganguli SK, Rekha PP, Gupta N, Charan UA. AIDS awareness among undergraduate students. Maharashtra Ind J Pub Health 2002; 36:8-12.

10. Paul D, Gopalkrishanan. Knowledge regarding modes of transmission and prevention of sexually transmitted diseases including HIV/AIDS among child development project officers. Ind J Com Med 2001; 26:141-4.

11. Pratinidhi AK, Gokhale RM, Karad SR. Evaluation of sex education and AIDS prevention project in secondary schools of Pune City. Indian J Com Med 2001; 26:155-61.

12. Report of Rapid Household Survey of RCH in 1998 by Govt of India \& Taleem Research Foundation, Ahmedabad.Pg 51.

13. Bhatia V, Swami HM, Kaur AP. An intervention study to enhance AIDS awareness among underprivileged population in Chandigarh. Indian J Dermatol Venereol Leprol 2004;70:87-91

14. Dwijendra Nath Gangopadhyay. Evaluation of Sexually Transmitted Diseases/Human Immunodeficiency Virus Intervention Programs for Sex Workers in Calcutta, India. Sex Transm Dis. 2005 November; 32(11): 680-4.

15. Nagelkerke NJ, Jha P, de Vlas SJ, et al. Modelling HIV/AIDS epidemics in Botswana and India: impact of interventions to prevent transmission. Bull World Health Organ. 2002; 80:419-20.

16. SB Bhosale, SL Jadhav, Samir A Singru, Amitav Banerjee. Behavioral surveillance survey regarding human immunodeficiency virus/acquired immunodeficiency syndrome among high school and junior college students. Ind J Dermatology, Venereology \& Leprology (IJDVL), 2010; 76 (1): 33-7.

17. Raizada N, Samasundaram. C, Mehta J P, Pandya V. P- Effectiveness of various IEC in improving awareness and reducing stigma related to HIV/STD among school going teenagers. Indian Journal of Community Medicine Vol.XXX, No-1, Jan-Mar 2004.

18. Prabhakaran B. Behavioral surveillance survey (BSS) - experience from Maharashtra. Souvenir of the 4th West Bengal Sexual Health Conference Kolkata 2003; Abstract No 53 pg-34.

19. Giron CAH, Valdez AC, Trenado MQ, Salas FU, Peruga A, Avila MH. Factors associated with condom use in the male population of Mexico City. Int J STD AIDS 1999; 10:112-7.

20. Agha $S$ and Van Rossem R. Impact of a school based peer sexual health intervention on normative beliefs, risk perceptions, and sexual behavior of Zambian adolescents, Journal of Adolescent Health 2004, 34(5) 441-452. Ref ID : 9197 
Table 1: Sources of knowledge regarding HIV/AIDS

\begin{tabular}{|l|l|l|l|}
\hline Sources of knowledge & $\begin{array}{l}\text { Male (\%) } \\
\mathrm{n}=100^{*}\end{array}$ & $\begin{array}{l}\text { Female (\%) } \\
\mathrm{n}=108^{*}\end{array}$ & $\begin{array}{l}\text { Total (\%) } \\
\mathrm{n}=208^{*}\end{array}$ \\
\hline Radio & $09(9)$ & $4(3.70)$ & $13(6.25)$ \\
\hline T.V & $58(58)$ & $62(57.41)$ & $120(57.69)$ \\
\hline Health education(FHAC) & $29(29)$ & $36(33.33)$ & $65(31.25)$ \\
\hline Books/magazines & $01(1)$ & $00(0.00)$ & $01(0.48)$ \\
\hline Newspaper/Posters & $00(0)$ & $00(0)$ & $00(0)$ \\
\hline Friends/Relatives & $03(3)$ & $06(5.55)$ & $09(4.33)$ \\
\hline
\end{tabular}

* Sources of knowledge were asked only from those 100 males \& 108 females who said that they have heard about AIDS

Table 2: Knowledge and attitude of study subjects (Who have heard about HIV/AIDS) before Intervention, just after Intervention $\&$ three months after Intervention

\begin{tabular}{|c|c|c|c|c|c|c|c|c|c|}
\hline \multirow[t]{2}{*}{ Questions } & \multicolumn{3}{|c|}{ Before Intervention } & \multicolumn{3}{|c|}{ Just after Intervention } & \multicolumn{3}{|c|}{3 months after Intervention } \\
\hline & $\begin{array}{l}\text { Male } \\
(\%) \\
n=100\end{array}$ & $\begin{array}{l}\text { Female } \\
(\%) \\
n=108\end{array}$ & $\begin{array}{l}\text { Total } \\
(\%) \\
n=208 \\
\end{array}$ & $\begin{array}{l}\text { Male } \\
(\%) \\
n=100 \\
\end{array}$ & $\begin{array}{l}\text { Female } \\
(\%) \\
n=108\end{array}$ & $\begin{array}{l}\text { Total } \\
(\%) \\
n=208 \\
\end{array}$ & $\begin{array}{l}\text { Male } \\
(\%) \\
n=94\end{array}$ & $\begin{array}{l}\text { Female } \\
(\%) \\
n=100\end{array}$ & $\begin{array}{l}\text { Total } \\
(\%) \\
n=194 \\
\end{array}$ \\
\hline \multicolumn{10}{|c|}{ Regarding the modes of prevention } \\
\hline $\begin{array}{l}\text { Knows at least } \\
\text { two modes }\end{array}$ & $\begin{array}{l}73 \\
(73)\end{array}$ & $\begin{array}{l}64 \\
(59.26)\end{array}$ & $\begin{array}{l}137 \\
(65.86)\end{array}$ & $\begin{array}{l}87 \\
(87)\end{array}$ & $\begin{array}{l}76 \\
(70.37)\end{array}$ & $\begin{array}{l}163 \\
(78.36)\end{array}$ & $\begin{array}{l}72 \\
(76.60)\end{array}$ & $61(61)$ & $\begin{array}{l}133 \\
(68.56)\end{array}$ \\
\hline $\begin{array}{l}\text { One } \\
\text { misconception }\end{array}$ & $\begin{array}{l}76 \\
(76)\end{array}$ & $\begin{array}{l}82 \\
(75.9)\end{array}$ & $\begin{array}{l}158 \\
(76)\end{array}$ & $\begin{array}{l}20 \\
(20)\end{array}$ & $\begin{array}{l}30 \\
(27.8)\end{array}$ & $50(24)$ & $\begin{array}{l}43 \\
(45.7)\end{array}$ & $51(51)$ & $\begin{array}{l}94 \\
(48.4)\end{array}$ \\
\hline \multicolumn{10}{|c|}{ Regarding attitude towards HIV positive persons } \\
\hline $\begin{array}{l}\text { Two positive } \\
\text { attitudes or } \\
\text { more }\end{array}$ & $\begin{array}{l}69 \\
(69)\end{array}$ & $\begin{array}{l}64 \\
(59.2)\end{array}$ & $\begin{array}{l}133 \\
(63.9)\end{array}$ & $\begin{array}{l}90 \\
(90)\end{array}$ & $\begin{array}{l}85 \\
(78.7)\end{array}$ & $\begin{array}{l}175 \\
(84.1)\end{array}$ & $\begin{array}{l}77 \\
(81.9)\end{array}$ & $\begin{array}{l}71 \\
(71)\end{array}$ & $\begin{array}{l}148 \\
(76.3)\end{array}$ \\
\hline $\begin{array}{l}\text { Two negative } \\
\text { attitudes or } \\
\text { more }\end{array}$ & $\begin{array}{l}26 \\
(26)\end{array}$ & $\begin{array}{l}43 \\
(39.8)\end{array}$ & $\begin{array}{l}69 \\
(33.2)\end{array}$ & $2(2)$ & $7(6.5)$ & $9(4.3)$ & $\begin{array}{l}11 \\
(11.7)\end{array}$ & $16(16)$ & $\begin{array}{l}27 \\
(13.9)\end{array}$ \\
\hline
\end{tabular}

Table 3: Sexual practices and condom usages with non regular partner

\begin{tabular}{|c|c|c|c|c|}
\hline \multicolumn{2}{|c|}{ Sexual practices \& condom usage pattern } & $\begin{array}{l}\text { Male } \\
\text { (\%) }\end{array}$ & $\begin{array}{l}\text { Female } \\
(\%)\end{array}$ & $\begin{array}{l}\text { Total } \\
\text { (\%) }\end{array}$ \\
\hline \multicolumn{2}{|c|}{$\begin{array}{l}\text { Sexual relationship with a non regular partner/CSW during } \\
\text { the past } 12 \text { months }\end{array}$} & $11(10.2)$ & $3(2.3)$ & $14(5.9)$ \\
\hline \multicolumn{2}{|c|}{$\begin{array}{l}\text { Condom used in the last sexual act with a non regular } \\
\text { partner }\end{array}$} & $6(54.5)$ & $1(33.3)$ & $7(50)$ \\
\hline \multirow{4}{*}{$\begin{array}{l}\text { Frequency of condom usage in sexual act with } \\
\text { non regular partner/ in the last } 12 \text { months }\end{array}$} & Every time & $2(18.2)$ & $0(0)$ & $2(14.3)$ \\
\hline & Most time & $5(45.5)$ & $2(66.6)$ & $7(50)$ \\
\hline & Occasional & $3(27.3)$ & $1(33.3)$ & $4(28.5)$ \\
\hline & Never & $1(9.1)$ & $0(0)$ & $1(7.1)$ \\
\hline
\end{tabular}

